\title{
Analyzing the Popularity of Zoom Video Communications Using Marketing Mix Theory
}

\author{
Xueqian $\mathrm{Cao}^{1, *}$ \\ ${ }^{1}$ Faculty of Business And Economics, Monash University, Wellington Rd, Clayton VIC 3800, Melbourne Australia \\ "Corresponding author. Email: 1274001645@qq.com
}

\begin{abstract}
ASTRACT
Due to the global spread of the coronavirus pandemic, many organizations are now turning to remote video conferencing to conduct their daily work. Zoom Video Communications is one of the video conferencing companies that rise to prominence during Covid-19. This paper uses the 'product' and 'price' from Marketing Mix Theory to analyze Zoom's product-Zoom Video Business and compare it to another video conferencing platform, Google Meet. The conclusions drawn from this paper are that Zoom is popular during the pandemic since they meet the customers' capacity requirements like participants and licenses. In addition, Zoom's basic features, such as cloud storage and privacy setting, also satisfy the needs of customer. In the future, although Covid-19 may become better and the number of customers may decrease, people will still be willing to use Zoom as their "work at home" video conferencing platform compared with other platforms.
\end{abstract}

Keywords: Covid-19, Zoom Video Communications, Zoom Meetings Business, Google Meet, 4Ps, Marketing Mix Theory

\section{INTRODUCTION}

Zoom Video Communications, Inc is a company headquartered in San Jose, California that provides video telephony and online chat services to meet the remote teleconferencing needs of various people or groups. With the Corona Virus 2019 pandemic outbreak causing cities across the world to be quarantined and schools and universities to close, Zoom had become one of the primary tools for keeping businesses running, students studying and people socializing (Konrad, [5]). Konrad [5] claimed that according to mobile intelligence firm Apptopia, nearly 3 million people worldwide have downloaded the Zoom app for the first time since the COVID-19 pandemic emerged through March 28, 2020, bringing it to more than 59 million downloads since its launch in April 2019.

The marketing mix is a conceptual framework that marketing managers use when making the key decisions about allocating products to meets customers' requirements (Palmer, [6]). Palmer [6] also commented that the traditional marketing mix consists of 4 elements which are product, price, promotion, and price. Additionally, McCarthy (1960, as cited in Festa et al.,
[3]) stated that ' $[\mathrm{t}] \mathrm{he} 4 \mathrm{Ps}$ (product, price, promotion and place) constitute the traditional theoretical framework to implement the operational phase of the marketingmanagement process.' In this paper, the "product" and "price" in the Marketing Mix Theory will be used to analyze why people prefer Zoom as a tool for working, learning, and socializing during the COVID-19 pandemic period and whether Zoom will continue to be popular in the future.

\section{ANALYSIS}

\subsection{Analysis of product-Zoom Meetings Business}

Zoom Meetings Business was popular during the COVID-19 because most people were from private companies (55/108), as shown in Figure 1. Cawley [2] stated that this product is suitable for medium and large businesses. Zoom Meetings Business allows people to host meetings up tof 300 participants without a time cap and up to 99 licenses (Cawley, [2]). In addition, Cawley [2] demonstrated that this product will provide customers with a live chat support, as well as an additional phone 
support option for more extensive customer service. Furthermore, Zoom has basic features such as custom background settings for meetings, screen/file sharing, screen recording and customer privacy settings (Singh \& Awasthi, [8]). According to the survey conducted by Archibald et al. [1], some participants (44\%) considered Zoom's screen and file sharing options to promote people's engagement and rapport in meetings. For screen recording, this product provides recording transcripts, and if the customer starts using the recording function with transcripts, Zoom can store the recording in its own database and in your laptop. Grant [4] wrote that this company continues to purchase cloud-computing services and use Amazon's cloud service to provide highcapacity recording storage even during the Coronavirus period. With the popularity of zoom, the phenomenon of 'Zoombing' like religious gatherings has gradually emerged, causing customers to dispute the safety of Zoom (Grant,[4]). Grant [4] stated that to enhance privacy protection, this company purchased Keybase, a secure messaging firm, to provide the highest standard of encryption technology for the Zoom platform and employed network security experts to guide safety work. Similarly, each Zoom meeting is password-protected to prevent extraneous people from entering the meeting (Singh \& Awasthi, [8]).

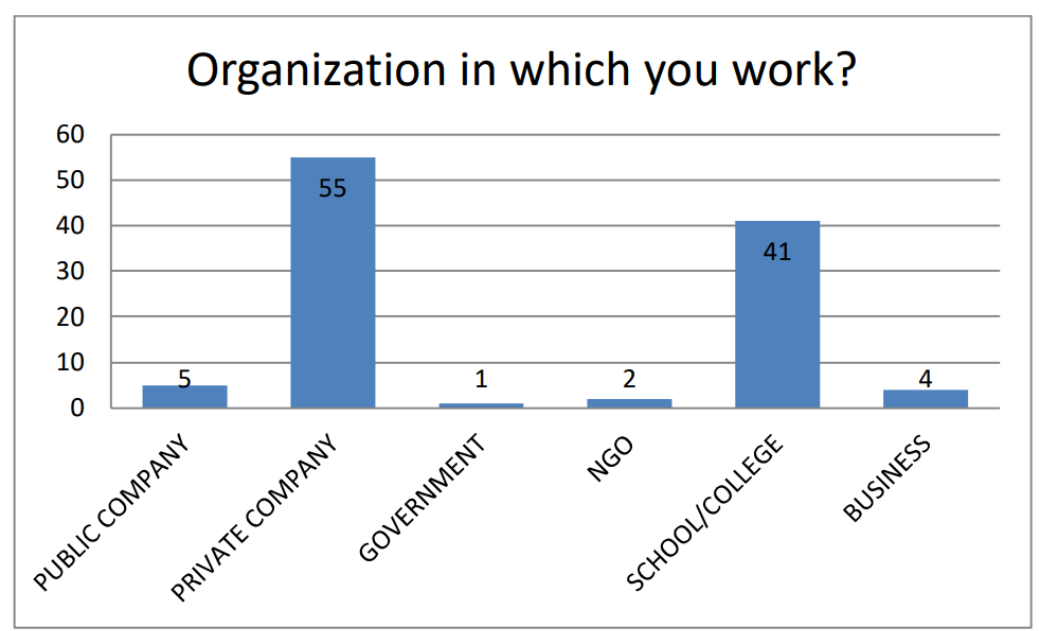

Figure 1. Organization in which you work. Adapted from 'A STUDY ON USAGE OF VCAAS (VIDEO CONFERENCING AS A SERVICE) PROVIDER WITH RESPECT TO ZOOM VIDEO COMMUNICATIONS DURING COVID-19 IN JAIPUR'. Copyright (2021) by Towards Excellence.

As seen from Figure 2, Zoom and Google Meet have the same customer support rating, so the two applications will be compared below. Google Meet's security and privacy can be compared to that of Zoom since Singh and Awasthi [8] concluded that Google Meet has a range of anti-abuse protections, including anti-hijacking measures for conferencing and dial-in, to ensure user's meetings are secure. In addition, Google Meet also has encryption measures, which contain that all data is encrypted by default during transmission video conferencing between Google and customer meetings on the web, Apple IOS applications (Singh \& Awasthi,[8] ). However, compared to Zoom, Google Meet may not be the first choice for hosting large group meetings, as only one person can share their screen at a time and the group size is limit to 100 to 250 people on paid plans (Patrick, [7]). In addition, as illustrated in Figure 3, Somani [9] noted that after Covid-19, most respondents $(72.22 \%)$ who will use Zoom application they used during Coronavirus, and only $27.78 \%$ will switch to a different one. To a large extent, according to the survey conducted by Somani[9] , the large percentage of respondents (69\%) displayed in Figure 4 used Zoom primarily because of its ease of use and free vision. Therefore, it can be concluded that people prefer to use Zoom rather than Google Meet as their work-at-home platform, and after Coronavirus, Zoom will still be the choice of most people. 


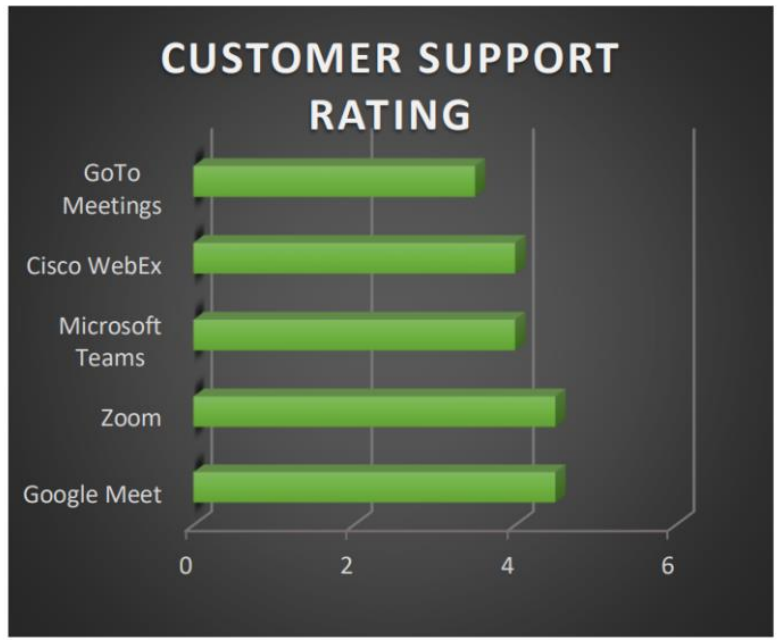

Figure 2. CUSTOMER SUPPORT RATING. Adapted from 'Updated Comparative Analysis on Video Conferencing Platforms-Zoom, Google Meet, Microsoft Teams, WebEx Teams and GoToMeetings'. Copyright (2020) by EasyChair.

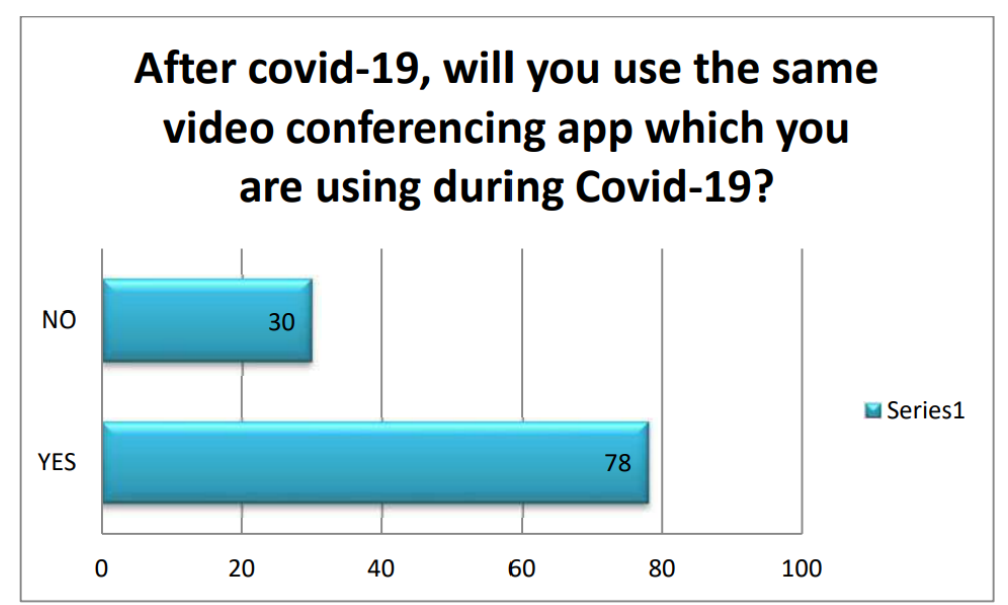

Figure 3. After covid-19, will you use the same video conferencing app which you are using during Covid-19? Adapted from 'A STUDY ON USAGE OF VCAAS (VIDEO CONFERENCING AS A SERVICE) PROVIDER WITH RESPECT TO ZOOM VIDEO COMMUNICATIONS DURING COVID-19 IN JAIPUR’. Copyright (2021) by Towards Excellence.

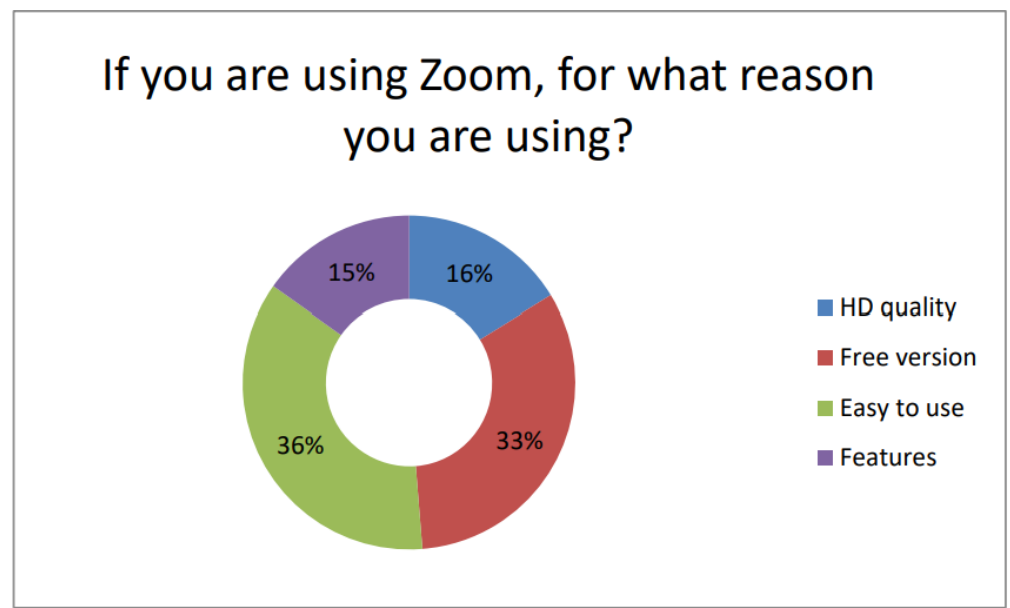

Figure 4. If you are using Zoom, for what reason you are using? Adapted from 'A STUDY ON USAGE OF VCAAS (VIDEO CONFERENCING AS A SERVICE) PROVIDER WITH RESPECT TO ZOOM VIDEO COMMUNICATIONS DURING COVID-19 IN JAIPUR'. Copyright (2021) by Towards Excellence. 


\subsection{Analysis of price for Zoom Meetings Business}

Zoom Meeting Business pricing plan offers more features, and up to 300 attendees and up to 99 licenses at a low cost of $\$ 19.99$ per month per license (Cawley,[2]). Somani [9] stated that from the statistics shown in Figure 5 , the majority of respondents $(85.19 \%)$ were using a non-paid service, which meant that people used the free version provided by the company, while the remaining $14.81 \%$ were using a paid service. It can be concluded that the majority of companies chose Zoom Meeting Business pricing plan, so that employees could enjoy non-paid services. Grant [4] pointed out that between the start of Covid-19 and April 30, 2020, sales of Zoom skyrocketed and Zoom expected to generate up to $\$ 1.8$ million in revenue in this fiscal year, which is almost three times the size of last year's business. Equally, as sales increased sharply to $\$ 328.2$ million, Zoom's cost of revenue, which consists of the cost of running its own data centres and paying cloud providers such as Amazon for additional capacity, jumped more than 4 times in the last quarter from a year ago to $\$ 103.7$ million (Tilley, [10] ). As a result, it is clear from the sales statistics above that Zoom's fee-based products such as Zoom Meeting Business pricing plan are popular, and people may be more likely to use Zoom products after coronavirus.

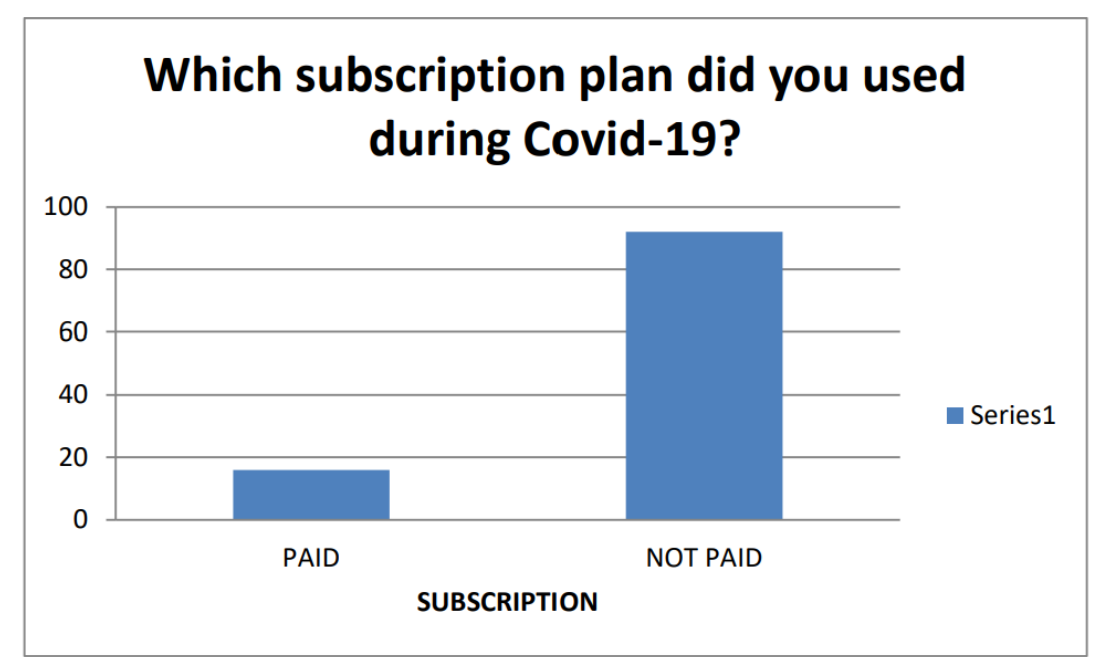

Figure 5. Which subscription plan did you used during Covid-19? Adapted from 'A STUDY ON USAGE OF VCAAS (VIDEO CONFERENCING AS A SERVICE) PROVIDER WITH RESPECT TO ZOOM VIDEO COMMUNICATIONS DURING COVID-19 IN JAIPUR'. Copyright (2021) by Towards Excellence.

\section{CONCLUSION}

To sum up, Zoom Video Communication is growing rapidly, and its product-Zoom Meeting Business is being embraced by many medium and large companies during the Coronavirus pandemic period. The "product" and "price" in the 4Ps theory are used to analyze the reasons for Zoom's popularity and the likelihood that people would still opt for Zoom after Covid-19. Zoom Meeting Business product meets customers' needs for a number of attendees and number of licenses. Moreover, more comprehensive customer service and some basic features such as a live chat, screen recording, and privacy settings are covered in Zoom Meeting Business. Compared to Zoom, although Google Meet's privacy features are also strong, the 250-person cap in case of a fee and the rule that only one person is allowed to share the screen in a meeting make Google Meet less popular among large firms. Regarding to the 'price', Zoom Meeting Business pricing plan of $\$ 19.99$ per month per license is reasonable for large companies, as this product includes many features that can better serve customers. Although it is a paid product, Zoom Meeting Business products are selling well as they have been growing since Covid-19. Furthermore, even after Covid-19, people still prefer Zoom to other video conferences. Not only because it has a reasonable price and a large enough capacity for participants and licenses, but also because of Zoom's simplicity. However, in the future, when the Coronavirus pandemic gets better, people might be more willing to work outside rather than at home by themselves, so the number of people using Zoom may decline.

\section{AUTHORS' CONTRIBUTIONS}

This paper is independently accomplished by the author.

\section{ACKNOWLEDGEMENTS}

I would like to express my deepest appreciation to my project Professor Sun, teaching assistant -YunQing Zhang and thesis advisor-Min Han. Professor Sun was instrument in guiding my interest in Financial Markets. Moreover, teaching assistant extended a great amount of assistance in understanding the underlying finance concepts and giving me some advice in writing thesis. 
Additionally, my thesis advisor gave me valuable advice in outlining the framework of my dissertation and in revising it.

\section{REFERENCES}

[1] Archibald, M. M., Ambagtsheer, R. C., Casey, M. G., \& Lawless, M. (2019). Using zoom videoconferencing for qualitative data collection: perceptions and experiences of researchers and participants. International Journal of Qualitative Methods, 18, 1609406919874596.

[2] Cawley, C. (Feb 4th, 2021). Zoom Pricing GuideUpgrading from Free Video Calling. Retrieved July 20, 2021, from https://tech.co/webconferencing/zoom-pricing-guide

[3] Festa, G., Cuomo, M. T., Metallo, G., \& Festa, A. (2016). The (r)evolution of wine marketing mix: From the 4Ps to the 4Es. Journal of Business Research, 69(5), 1550-1555. https://doi.org/10.1016/j.jbusres.2015.10.015

[4] Grant, N. (2020). Zoom Transforms Hype Into Huge Jump in Sales, Customers. Bloombery.Com, N.PAG.

[5] Konrad, A. (2020). Zoom Kaboom! Forbes, 203(2), $76-85$

[6] Palmer, A. (2012). Introduction to marketing: Theory and practice (3rd Ed.). Oxford: Oxford University Press.

[7] Patrick, B. (2021). Zoom vs. Teams vs. Google Meet: Which is right for you? Journal of Accountancy, 14.

[8] Singh, R., \& Awasthi, S. (2020). Updated Comparative Analysis on Video Conferencing Platforms-Zoom, Google Meet, Microsoft Teams, WebEx Teams and GoToMeetings. EasyChair: The World for Scientists, 1-9.

[9] Somani, M. A. (2021). A STUDY ON USAGE OF VCAAS (VIDEO CONFERENCING AS A SERVICE) PROVIDER WITH RESPECT TO ZOOM VIDEO COMMUNICATIONS DURING COVID-19 IN JAIPUR.

[10] Tilley, A. (2020, July 16). Zoom Targets Prolonged Remote-Work Era as Coronavirus Drags On. Wall Street Journal - Online Edition, N.PAG. 